\title{
Multidisciplinary Integrated Metabolic Rehabilitation in Elderly Obese Patients: Effects on Cardiovascular Risk Factors, Fatigue and Muscle Performance
}

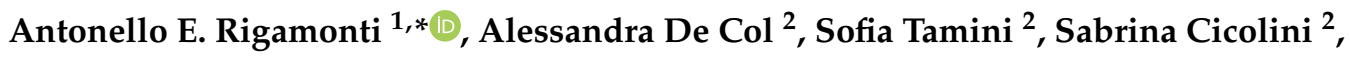 \\ Diana Caroli $^{2}$, Roberta De Micheli ${ }^{2}$, Gabriella Tringali ${ }^{2}$, Laura Abbruzzese 2,3, \\ Nicoletta Marazzi ${ }^{2}$, Silvano G. Cella ${ }^{1}$ and Alessandro Sartorio ${ }^{2,3}$ \\ 1 Department of Clinical Sciences and Community Health, University of Milan, via Vanvitelli 32, 20129 Milan, \\ Italy; silvano.cella@unimi.it \\ 2 Istituto Auxologico Italiano, IRCCS, Experimental Laboratory for Auxo-Endocrinological Research, strada L. \\ Cadorna 90, 28824 Piancavallo (VB), Italy; a.decol@auxologico.it (A.D.C.); s.tamini@auxologico.it (S.T.); \\ s.cicolini@auxologico.it (S.C.); d.caroli@auxologico.it (D.C.); r.demicheli@auxologico.it (R.D.M.); \\ g.tringali@auxologico.it (G.T.); 1.abbruzzese@auxologico.it (L.A.); n.marazzi@auxologico.it (N.M.); \\ sartorio@auxologico.it (A.S.) \\ 3 Istituto Auxologico Italiano, IRCCS, Division of Metabolic Diseases, strada L. Cadorna 90, \\ 28824 Piancavallo (VB), Italy \\ * Correspondence: antonello.rigamonti@unimi.it; Tel.: +39-02-503-17013; Fax: +39-02-503-17011
}

Received: 13 May 2019; Accepted: 28 May 2019; Published: 31 May 2019

check for updates

\begin{abstract}
Background: Obesity is a widespread problem in the elderly, being associated with severe comorbidities negatively influencing life expectancy. Integrated multidisciplinary metabolic rehabilitation aimed to reduce body weight (BW) and fatigue, increase physical autonomy and introduce healthy life style changes has been proposed as a useful intervention to improve the general health status and quality of life of the obese geriatric population. Methods: Six hundred-eighty four severely obese subjects ( $\mathrm{F} / \mathrm{M}=592 / 92$; age range: $61-83$ years; mean body mass index, $\mathrm{BMI} \pm \mathrm{SD}$ : $42.6 \pm 5.6 \mathrm{~kg} / \mathrm{m}^{2}$ ) were admitted to take part in a three-week in-hospital BW reduction program (BWRP), entailing energy restricted diet, psychological counselling, physical rehabilitation and nutritional education. Biochemical parameters, cardiovascular risk factors (throughout the Coronary Heart Disease Risk, CHD-R), fatigue (throughout the Fatigue Severity Scale, FSS) and lower limb muscle performance (throughout the Stair Climbing Test, SCT) were evaluated before and at the end of the BWRP. Results: A 4\% BW reduction was achieved at the end of the BWRP. This finding was associated with a significant improvement of the metabolic homeostasis (i.e., decrease in total cholesterol and glucose) and a reduction of systolic blood pressure in both females and males, thus resulting in a reduction of CHD-R in the male group. Total FSS score and SCT time decreased in female and male obese patients. The effects of BWPR were comparable among all age-related subgroups ( $>60,60-69$ and $>70$ years), apart from $\triangle$ CHD-R, which was higher in male subgroups. Finally, age was negatively correlated with $\triangle \mathrm{BMI}$ and $\triangle \mathrm{FSS}$. Conclusions: Though only a relatively limited number of outcomes were investigated, the present study shows that a $4 \%$ BW reduction in severely elderly obese patients is associated with positive multisystemic effects, particularly, muscle-skeletal and cardiometabolic benefits, which can favorably influence their general well-being and improve the autonomy level in performing more common daily activities. The maintenance of a healthy life style, including controlled food intake and regular physical activity, after a BWRP is obviously recommended in all elderly obese patients to further improve their clinical condition.
\end{abstract}

Keywords: multidisciplinary integrated metabolic rehabilitation; diet; exercise; geriatric obesity 


\section{Introduction}

In the last decade, we have assisted a dramatic worldwide increase in geriatric population and, concomitantly, in obesity [1]. Thus, the elderly obese patient is becoming an increasingly prevalent phenotype in the general population from developed and also developing countries, with relevant socioeconomic implications for the public health system and political decision-making [2].

Geriatric obesity is associated with a worsening of the coronary heart disease risk (CHD-R), due to dyslipidemia, hypertension, type 2 diabetes mellitus and physical inactivity [3]. Furthermore, functional autonomy and, in general, the quality of life are consistently reduced in an elderly obese subject, so that obesity can be considered a determinant of "frailty" in geriatric practice and have a prominent causative role for several clinical conditions that require hospitalization or institutionalization [4]. Finally, elderly women seem to be at high risk to develop or maintain a pre-existing obesity due the well-known post-menopausal changes [5].

Body weight (BW) reduction programs (BWRPs) have been demonstrated to be a valid strategy to contrast the negative effects associated with geriatric obesity, particularly when a multidisciplinary integrated approach is adopted. In this context, diet combined with physical activity and psychological counseling has been shown to be more effective when administered in cohorts of elderly obese patients in comparison with the single interventions [6].

Nevertheless, some controversies regarding the short- and long-term benefits and safety of BWRPs against geriatric obesity still persist [4].

For instance, elderly subjects have been reported to have lower resting energy expenditure and caloric requirements, with the consequence that a BWRP may induce an unsatisfactory negative energy balance and a negligible weight loss [7-10].

In addition, since sarcopenic obesity is more prevalent in elderly than young individuals, a protein-restricted dietetic regimen administered to an elderly obese patient could increase the catabolism of muscle proteins, a process amplified by the obesity-associated low-grade chronic inflammation and aging-related hypomotility [11,12]. Weight loss obtained in an elderly obese patient undergoing caloric restriction may derive from a relevant shrinkage of lean mass (more than $25 \%$ ), with possible reduction in muscle strength, limitations in motor function and impairment of glucose tolerance, with muscle tissue being fundamental for glucose uptake and glucometabolic homeostasis [13-17].

Independently from age, weight loss reduces bone mass density, an effect that, in osteopenic or osteoporotic post-menopausal women, could be deleterious due the risk of fractures [18].

Finally, some authors have proposed the "obesity paradox" to indicate the protective value of a high BMI in later life [19]. In particular, the progression of some clinical conditions, frequently diagnosed in geriatric patients, such as cancer, chronic heart failure and end-stage renal disease, is slowed down to wasting syndrome or cachexia in the obese subgroup compared to the lean counterpart [20].

Based on these conflicting results, well highlightened by recent reviews $[4,6]$, there is the urgent need to evaluate adjunctive outcomes in order to define and quantify the effects of an (integrated) BWRP on cardiometabolic status, muscle performance and quality of life in elderly obese patients. Understanding of the beneficial effects of any BWRP on specific outcomes in different subgroups of elderly obese patients (e.g., for gender and age ranges) might allow us to define the demographic and clinical characteristics of the elderly obese patient who will favorably respond to a standardized BWRP and, additionally, to tailor each component of the BWRP (dietetic regimen, type/duration/intensity of physical activity, adherence to healthy life styles, concomitant pharmacological therapy etc.) to a particular elderly obese patient having specific demographic and clinical characteristics.

Therefore, the present study was aimed at investigating the effects of a three-week BWRP, administered to a large cohort of elderly obese females and males, on (1) CHD-R, a validated scoring system, including demographic, clinical, biochemical and cardiovascular parameters, which permits the calculation of CHD-R over the next 10 years and compare this value to that of others of the same age [21]; (2) stair climbing test (SCT), used to evaluate functional strength, balance and agility of lower 
limbs through ascending a set number of steps [22,23]; and (3) fatigue severity scale (FSS), a largely employed self-report questionnaires to evaluate fatigue in daily activities, which does not depend upon an underlying depressive condition [24].

\section{Material and Methods}

\subsection{Patients and Body Weight Reduction Program}

Six-hundred-eighty-four severely obese subjects (females, F/males, $M=592 / 92$; age range: 61-83 years; body mass index, BMI: $42.6 \pm 5.6 \mathrm{~kg} / \mathrm{m}^{2}$ ) were recruited at the Division of Metabolic Diseases, Istituto Auxologico Italiano, Piancavallo (VB), where they were hospitalized for a three-week multidisciplinary integrated BWRP, including hypocaloric diet, nutritional education, psychological counselling and moderate physical activity (see below for details). The sample size was considered adequate, taking into account a power analysis in which a mean value of $\triangle \mathrm{BMI}(\%)$ after BWRP was supposed to be equal to $4.0 \pm 4.0 \%$ with an $\alpha$ error of 0.05 at two tails and a power of 0.80 . The consort flow diagram is shown in Figure 1. The unique criterion of inclusion was a BMI $>35 \mathrm{~kg} / \mathrm{m}^{2}$, while the main exclusion criteria were physical inability in performing SCT and cognitive impairments hampering the FSS execution.

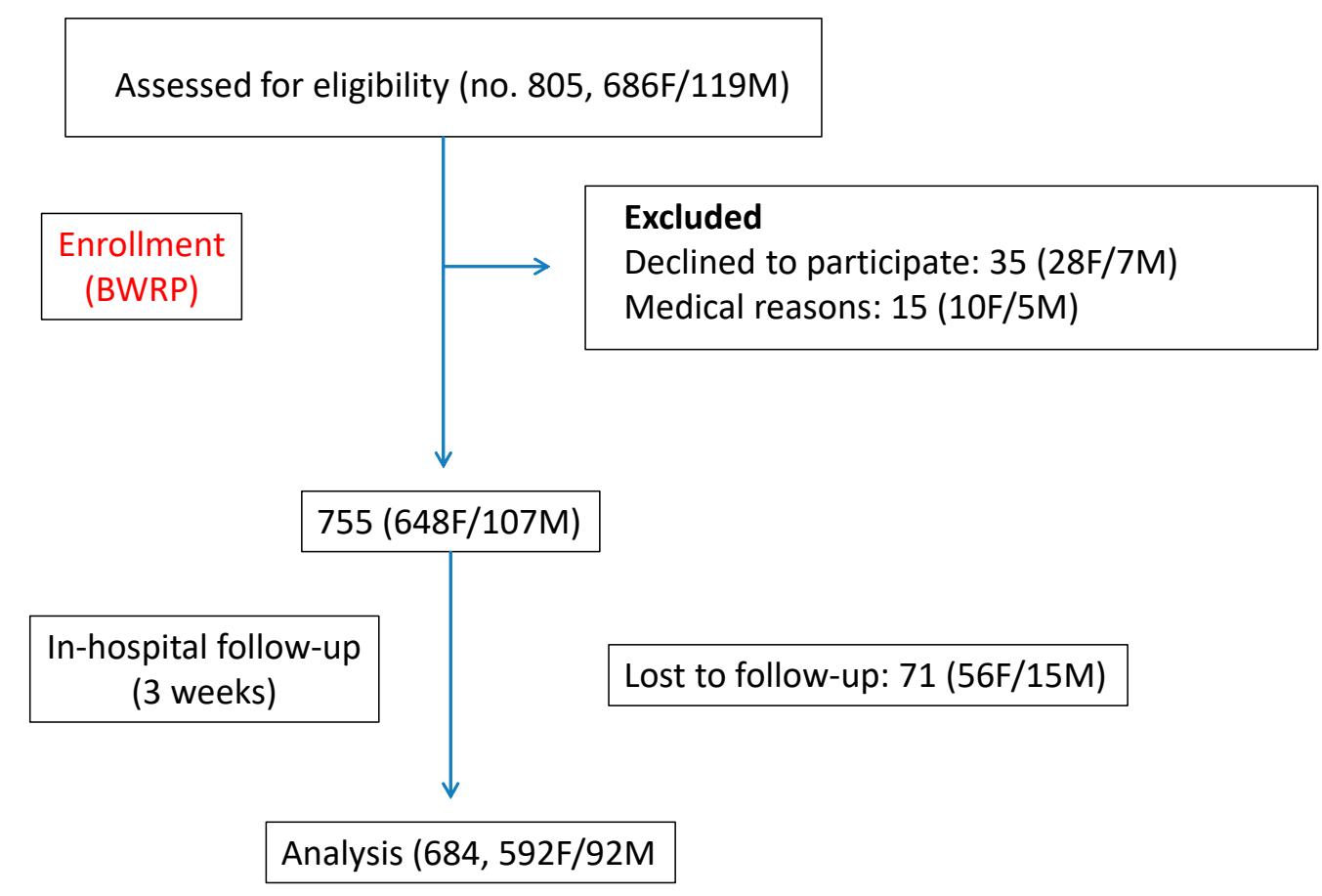

Figure 1. Consort flow diagram of the study. BWRP, body weight reduction program.

When considering the BWRP in detail, energy intake was restricted by imposing a diet (5023-7113 kJ/day, i.e., 1200-1700 kcal/day) containing about 21\% proteins, 53\% carbohydrates and $26 \%$ lipids. The calories to be given with the diet were calculated by subtracting approximately $25 \%$ from the value of resting energy expenditure as measured in each patient by indirect calorimetry (Vmax 29; SensorMedics Corporation, Yorba Linda, CA, USA) for a total duration of 20 min. Under the energy restriction, each patient was free to choose foods from a heterogeneous daily menu. Foods to which the patient declared to be allergic were removed from the menu. Five daily portions of fruits and vegetables were obligatory. A fluid intake of at least $1500 \mathrm{~mL} /$ day was encouraged. Nutritional education consisted of lectures, demonstrations and group discussions with and without a supervisor, took place every day throughout the whole rehabilitation period. Sessions of psychological counselling were conducted by clinical psychologists 2-3 times/week and were based on individual or cognitive 
behavioral strategies. Physical activity consisted of five training sessions/week (about $1 \mathrm{~h}$ each session), including indoor light jogging, dynamic exercises of the upper and lower limbs (standing and floor gymnastics routines, focalized on muscle strength-power development) at moderate intensity under the guide of a therapist; furthermore, subjects underwent either 15-20 min aerobic exercise or $2 \mathrm{~km}$ outdoor walking on a predetermined track, according to individual capabilities and clinical status.

Before and after BWRP, each subject underwent the following tests/evaluations, which are described in detail below:

-SCT (stair climbing test);

-FSS (fatigue severity score);

-CHD-R (coronary heart disease risk);

-Standard hematochemistry.

The protocol was approved by the local Ethical Committee (research project code: 18A301, acronym: FUOBAUXO); all subjects gave their written consent after being fully informed of the nature and procedures of the study.

\subsection{Stair Climbing Test}

SCT is a well-standardized procedure, which was readapted and validated by our group to measure the maximal anaerobic power $[22,23,25]$. Subjects were invited to climb up ordinary stairs (13 steps of $15.3 \mathrm{~cm}$ each, vertical distance: $1.99 \mathrm{mt}$ ) at the highest possible speed, according to their capabilities. The stairs were climbed one time by the participant. The time taken to perform the test was measured by an experimental investigator with a digital stopwatch. In line with the assumptions by Margaria et al. [26], anaerobic power (in W) was calculated by using the following formula:

$$
\text { (body weight } \times \text { 9:81 } \times \text { vertical distance)/time }
$$

where body weight, vertical distance and time are expressed in $\mathrm{kg}, \mathrm{m}$ and sec, respectively, and $9.81 \mathrm{~m} / \mathrm{sec}^{2}$ represents the acceleration of gravity. See also Reference [27] for further details.

\subsection{Fatigue Severity Scale}

FSS is one of the most commonly used self-report questionnaires for the fatigue assessment in chronic diseases [28,29], already used and validated in Italian obese patients by our group [24].

FSS consists of nine statements (items) describing the negative effects of fatigue on motivation, exercise, physical functioning, ability to carry out duties, work, family or social life. Responders are asked to rate each statement considering the previous week and using a Likert scale ranging from one (strong disagreement) to seven (strong agreement). The total score is computed by averaging the raw scores of each item.

\subsection{Evaluation of Coronary Heart Disease Risk}

Selected CHD-R factors, including systolic and diastolic blood pressures (SBP and DBP, respectively), total and high-density lipoprotein cholesterol (T-C and HDL-C, respectively), cigarette smoking and diabetes mellitus, were assessed in each subject [30]. Two BP determinations were made after the participant had been sitting at least $5 \mathrm{~min}$, being the mean value used for the subsequent analyses.

$\mathrm{BP}$ and T-C/HDL-C levels were considered without regard to the use of anti-hypertensive or lipid-lowering drugs. The diagnosis of diabetes mellitus was defined if the patient was under treatment with insulin or oral hypoglycemic agents or, alternatively, if fasting blood glucose levels exceeded $140 \mathrm{mg} / \mathrm{dL}$. Individuals who smoked at least one cigarette per day during the previous 12 months were classified as smokers. 
The CHD-R scores were estimated using a simple CHD prediction model developed by Wilson et al. [30], which takes into account gender, age, diabetes, smoking, BP, T-C and HDL-C categories.

This scoring scale, based on established, independent and biologically important risk factors for $\mathrm{CHD}$, represents a simplified approach to predict risk for initial CHD events in disease-free outpatients at 10 years.

CHD score sheets (for men and women) attribute different ranks in the function of classes of age (nine subgroups, from 30 up to 74 years), T-C (five subgroups, from $<160$ to $\geq 280 \mathrm{mg} / \mathrm{dL}$ ), HDL-C (five subgroups, from $<35$ up to $\geq 60 \mathrm{mg} / \mathrm{dL}$ ) and BP (SBP: Five subgroups, from $<120$ up to $\geq 160 \mathrm{mmHg}$; DBP: Five subgroups, from $<80$ up to $\geq 100 \mathrm{mmHg}$ ). Diabetes and smoking were defined into two categories (yes/no).

When SBP and DBP fell into different categories, the higher category was selected for the calculation of the CHD score.

\subsection{Hematochemical Testing}

Serum glucose level was measured by the glucose oxidase enzymatic method (Roche Diagnostics, Monza, Italy). The sensitivity of the method was $2 \mathrm{mg} / \mathrm{dL}$.

Colorimetric enzymatic-assays (Roche Diagnostics, Monza, Italy) were used to determine serum T-C and HDL-C levels. The sensitivities of the assays were $3.86 \mathrm{mg} / \mathrm{dL}$ and $3.09 \mathrm{mg} / \mathrm{dL}$, respectively.

\subsection{Statistical Analysis}

The Sigma Stat 3.5 statistical software package (Systat Software, San Jose, CA, USA) was used for data analyses and the GraphPad Prisma 5.0 software (GraphPad Software, San Diego, CA, USA) for data plotting.

The Shapiro-Wilk test showed that all parameters were normally distributed.

Results are reported as mean \pm SD (standard deviation). Each parameter, particularly BW, BMI, T-C, HDL-C, glucose, SBP, DBP, CHD-R, FSS score and SCT time, were evaluated not only as an absolute value, but also as a pre-post-BWRP difference ( $\Delta$ in the corresponding unit of measurement for CHD-R or \% for all remaining parameters).

All parameters were compared among all subgroups (all, females/males, $>60$ years, 60-69 years and $>70$ years) before and after BWRP by using a t-Student test (for paired or unpaired data) or one-way ANOVA, followed by the post hoc Tukey's test, if appropriate. A linear regression was applied to correlate each other parameter.

A level of significance of $p<0.05$ was used for all data analyses.

\section{Results}

As shown in Tables 1-3, WHR, height, BW and BMI were significantly higher in males than females for each age range ( $>60$ years, $60-69$ years and $>70$ years) $(p<0.01)$ before BWRP, while significantly lower HDL-C levels were found in males than females $(p<0.01)$. The CHD-R, FSS score and SCT time were significantly higher in females than males $(p<0.01)$, with the exception of the subgroups aged $>70$ years. Males or females aged $>70$ years had a significantly lower BW when compared to the other subgroups of the same gender (i.e., $>60$ years and $60-69$ years) $(p<0.01)$. BMI was significantly higher in females aged $60-69$ years than in those aged $>70$ years $(p<0.01)$. Females aged $>70$ years had a significantly higher SCT time than those belonging to the subgroup of the same gender, aged 60-69 years $(p<0.01)$. When pooling BW or BMI values of females and males (i.e., total), subjects aged $>70$ years had a significant lower BW or BMI than the remaining subgroups (i.e., $>60$ years and $60-69$ years) $(p<0.01)$. When pooling HDL-C levels of females and males (i.e., total), subjects aged $>70$ years had significant lower HDL-C levels than the subgroup aged 60-69 years $(p<0.01)$. CHD-R was significantly higher in subjects aged 60-69 years than in those aged $>70$ years, including both females and males $(p<0.01)$. 
Table 1. Demographic and anthropometric characteristics of the study population (before and after BWRP).

\begin{tabular}{|c|c|c|c|c|c|c|c|c|c|}
\hline \multirow[b]{2}{*}{ Parameter } & \multicolumn{3}{|c|}{ Total } & \multicolumn{3}{|c|}{ Males } & \multicolumn{3}{|c|}{ Females } \\
\hline & $>60$ Year & 60-69 Year & $>70$ Year & $>60$ Year & 60-69 Year & $>70$ Year & $>60$ Year & 60-69 Year & $>70$ Year \\
\hline No. & 684 & 500 & 184 & 92 & 69 & 23 & 592 & 432 & 160 \\
\hline Age (year) & $67.7 \pm 4.7$ & $64.7 \pm 2.6$ & $73.4 \pm 3.1$ & $67.0 \pm 4.8$ & $64.7 \pm 2.5$ & $74.1 \pm 2.6$ & $67.1 \pm 4.7$ & $64.7 \pm 2.6$ & $73.4 \pm 3.1$ \\
\hline WHR & $1.0 \pm 0.1$ & $0.9 \pm 0.1$ & $1.0 \pm 0.1$ & $1.0 \pm 0.1^{\mathrm{a}}$ & $1.0 \pm 0.1^{\mathrm{a}}$ & $1.0 \pm 0.1^{\mathrm{a}}$ & $0.9 \pm 0.1$ & $0.9 \pm 0.1$ & $0.9 \pm 0.1$ \\
\hline Height (m) & $1.6 \pm 0.1$ & $1.6 \pm 0.1$ & $1.6 \pm 0.1$ & $1.7 \pm 0.1^{\mathrm{a}}$ & $1.7 \pm 0.1^{\mathrm{a}}$ & $1.6 \pm 0.1^{\mathrm{a}}$ & $1.5 \pm 0.1$ & $1.5 \pm 0.1$ & $1.5 \pm 0.1$ \\
\hline PRE-BW (kg) & $104.3 \pm 15.7$ & $106.0 \pm 16.4$ & $99.6 \pm 12.3$ & $114.8 \pm 16.8^{\mathrm{a}}$ & $118.1 \pm 16.7^{\mathrm{a}}$ & $104.9 \pm 12.6^{\mathrm{a}, \mathrm{b}}$ & $102.6 \pm 14.9$ & $104.0 \pm 15.5$ & $98.8 \pm 12.1^{b}$ \\
\hline POST-BW (kg) & $100.3 \pm 15.2^{c}$ & $101.8 \pm 15.9^{c}$ & $96.4 \pm 12.2^{\mathrm{c}}$ & $110.1 \pm 16.3^{c}$ & $113.3 \pm 16.3^{c}$ & $98.8 \pm 14.4^{c}$ & $98.8 \pm 14.4^{\mathrm{c}}$ & $99.9 \pm 15.0^{\mathrm{c}}$ & $95.7 \pm 12.0^{\mathrm{c}}$ \\
\hline$\Delta \mathrm{BW}(\%)$ & $4.7 \pm 9.2$ & $4.8 \pm 8.7$ & $4.4 \pm 10.3$ & $5.3 \pm 10.1$ & $5.7 \pm 11.6$ & $4.0 \pm 1.5$ & $4.6 \pm 9.0$ & $4.6 \pm 8.1$ & $4.4 \pm 11.1$ \\
\hline PRE-BMI (kg/m²) & $42.6 \pm 5.6$ & $43.0 \pm 5.9$ & $41.4 \pm 4.8^{\mathrm{d}}$ & $40.6 \pm 4.8^{\mathrm{e}}$ & $41.1 \pm 4.6^{\mathrm{e}}$ & $38.9 \pm 5.0^{\mathrm{e}}$ & $42.9 \pm 5.7$ & $43.3 \pm 6.0$ & $41.8 \pm 4.7^{\mathrm{f}}$ \\
\hline POST-BMI $\left(\mathrm{kg} / \mathrm{m}^{2}\right)$ & $41.0 \pm 5.5^{c}$ & $41.3 \pm 5.7^{c}$ & $40.0 \pm 4.8^{c}$ & $38.9 \pm 4.7^{c}$ & $39.4 \pm 4.6^{c}$ & $37.4 \pm 4.8^{c}$ & $41.3 \pm 5.6^{c}$ & $41.6 \pm 5.8^{c}$ & $40.5 \pm 4.7^{\mathrm{c}}$ \\
\hline$\Delta$ BMI $(\%)$ & $4.0 \pm 2.1$ & $4.2 \pm 1.8$ & $3.5 \pm 2.8$ & $4.2 \pm 1.7$ & $4.3 \pm 1.7$ & $4.0 \pm 1.6$ & $3.9 \pm 2.2$ & $4.1 \pm 1.8$ & $3.4 \pm 3.0$ \\
\hline
\end{tabular}

Values are expressed as mean \pm SD. ${ }^{a} p<0.01$ compared to the corresponding female subgroup of the same age; ${ }^{\mathrm{b}} p<0.01$ compared to the subgroups of the same gender, aged $>60$ years and 60-69 years; ${ }^{c} p<0.01$ compared to the corresponding subgroup before BWRP; $\mathrm{d} p<0.01$ compared to the subgroups aged $>60$ years and $60-69$ years, including both females and males (i.e., total); $\mathrm{e} p<0.01$ compared to the corresponding female subgroup of the same age range; ${ }^{\mathrm{f}} p<0.01$ compared to the subgroup of the same gender, aged $60-69$ years. WHR, waist to hip circumference ratio; BW, body weight; BMI, body mass index; BWRP, body weight reduction program. 
Table 2. Biochemical and cardiovascular parameters of the study population (before and after BWRP).

\begin{tabular}{|c|c|c|c|c|c|c|c|c|c|}
\hline \multirow[b]{2}{*}{ Parameter } & \multicolumn{3}{|c|}{ Total } & \multicolumn{3}{|c|}{ Males } & \multicolumn{3}{|c|}{ Females } \\
\hline & $>60$ Year & 60-69 Year & $>70$ Year & $>60$ Year & 60-69 Year & $>70$ Year & $>60$ Year & 60-69 Year & $>70$ Year \\
\hline PRE-GLU (mg/dL) & $107.3 \pm 33.9$ & $108.3 \pm 35.4$ & $104.5 \pm 29.0$ & $105.4 \pm 28.0$ & $108.4 \pm 30.3$ & $96.1 \pm 16.7$ & $107.6 \pm 34.7$ & $108.2 \pm 36.2$ & $105.8 \pm 30.3$ \\
\hline POST-GLU (mg/dL) & $88.0 \pm 14.4^{\mathrm{a}}$ & $87.8 \pm 14.9^{\mathrm{a}}$ & $88.5 \pm 12.8^{\mathrm{a}}$ & $86.1 \pm 12.8^{\mathrm{a}}$ & $86.2 \pm 13.0^{\mathrm{a}}$ & $85.8 \pm 12.6^{\mathrm{a}}$ & $88.5 \pm 14.8^{\mathrm{a}}$ & $88.2 \pm 15.4^{\mathrm{a}}$ & $89.3 \pm 13.0^{\mathrm{a}}$ \\
\hline$\Delta \mathrm{GLU}(\%)$ & $10.6 \pm 14.5$ & $10.9 \pm 14.7$ & $9.6 \pm 13.9$ & $11.7 \pm 13.8$ & $11.2 \pm 15.6$ & $12.9 \pm 8.0$ & $10.2 \pm 14.8$ & $10.8 \pm 14.5$ & $8.5 \pm 15.6$ \\
\hline PRE-T-C (mg/dL) & $199.0 \pm 38.8$ & $199.2 \pm 39.8$ & $198.4 \pm 36.1$ & $193.7 \pm 36.1$ & $193.6 \pm 36.0$ & $194.0 \pm 37.3$ & $199.8 \pm 39.2$ & $200.1 \pm 40.3$ & $199.0 \pm 36.1$ \\
\hline POST-T-C (mg/dL) & $169.7 \pm 35.9^{a}$ & $170.0 \pm 36.2^{\mathrm{a}}$ & $168.8 \pm 34.8^{a}$ & $155.9 \pm 36.8^{a}$ & $156.4 \pm 39.4^{\mathrm{a}}$ & $154.6 \pm 28.0^{a}$ & $171.8 \pm 35.3^{a}$ & $172.2 \pm 35.3^{\mathrm{a}}$ & $170.6 \pm 35.3^{a}$ \\
\hline$\Delta \mathrm{T}-\mathrm{C}(\%)$ & $13.7 \pm 14.3$ & $13.5 \pm 14.0$ & $14.3 \pm 15.1$ & $17.9 \pm 16.7$ & $17.8 \pm 17.9$ & $18.2 \pm 12.6$ & $13.1 \pm 13.8$ & $12.8 \pm 13.2$ & $13.8 \pm 15.4$ \\
\hline PRE-HDL-C (mg/dL) & $50.9 \pm 13.5$ & $50.5 \pm 13.9$ & $51.7 \pm 12.1^{\mathrm{b}}$ & $40.9 \pm 9.2^{c}$ & $40.0 \pm 9.0^{\mathrm{c}}$ & $43.8 \pm 9.6^{c}$ & $52.4 \pm 13.4$ & $52.2 \pm 13.9$ & $52.9 \pm 12.1$ \\
\hline POST-HDL-C (mg/dL) & $42.7 \pm 10.3^{\mathrm{a}}$ & $42.6 \pm 10.6^{\mathrm{a}}$ & $43.0 \pm 9.3^{\mathrm{a}}$ & $35.6 \pm 7.9^{\mathrm{a}}$ & $34.8 \pm 7.8^{\mathrm{a}}$ & $38.1 \pm 7.8^{\mathrm{a}}$ & $43.8 \pm 10.2^{\mathrm{a}}$ & $43.8 \pm 10.5^{\mathrm{a}}$ & $43.8 \pm 9.3^{\mathrm{a}}$ \\
\hline$\Delta \mathrm{HDL}-\mathrm{C}(\%)$ & $14.8 \pm 13.7$ & $14.3 \pm 13.2$ & $16.0 \pm 15.0$ & $11.0 \pm 13.3$ & $10.9 \pm 13.8$ & $11.1 \pm 11.8$ & $15.4 \pm 13.7$ & $14.9 \pm 13.0$ & $16.7 \pm 15.3$ \\
\hline PRE-DBP (mmHg) & $77.6 \pm 8.2$ & $77.8 \pm 7.9$ & $76.9 \pm 8.8$ & $76.8 \pm 9.5$ & $78.0 \pm 9.0$ & $73.3 \pm 10.5$ & $77.7 \pm 7.9$ & $77.8 \pm 7.7$ & $77.4 \pm 8.4$ \\
\hline POST-DBP (mmHg) & $74.6 \pm 6.7^{\mathrm{a}}$ & $74.6 \pm 7.0^{\mathrm{a}}$ & $74.4 \pm 5.9^{a}$ & $74.7 \pm 7.5^{\mathrm{a}}$ & $74.9 \pm 7.9^{\mathrm{a}}$ & $74.3 \pm 6.2$ & $74.5 \pm 6.6^{\mathrm{a}}$ & $74.5 \pm 6.8^{a}$ & $74.5 \pm 5.9^{\mathrm{a}}$ \\
\hline$\triangle \mathrm{DBP}(\%)$ & $3.2 \pm 11.7$ & $3.5 \pm 10.8$ & $2.6 \pm 13.8$ & $2.7 \pm 16.8$ & $3.3 \pm 10.7$ & $1.0 \pm 28.7$ & $3.3 \pm 10.7$ & $3.5 \pm 10.8$ & $2.9 \pm 10.5$ \\
\hline PRE-SBP (mmHg) & $132.6 \pm 14.6$ & $132.3 \pm 14.4$ & $133.4 \pm 15.4$ & $131.5 \pm 14.5$ & $32.4 \pm 14.0$ & $128.6 \pm 16.0$ & $132.8 \pm 14.7$ & $132.2 \pm 14.5$ & $134.2 \pm 15.1$ \\
\hline POST-SBP (mmHg) & $123.8 \pm 10.2^{a}$ & $123.7 \pm 10.3^{a}$ & $124.0 \pm 9.9^{\mathrm{a}}$ & $123.9 \pm 11.1^{\mathrm{a}}$ & $124.0 \pm 11.4^{\mathrm{a}}$ & $123.6 \pm 10.4^{a}$ & $123.8 \pm 10.0^{a}$ & $123.7 \pm 10.1^{\mathrm{a}}$ & $124.1 \pm 9.9^{\mathrm{a}}$ \\
\hline$\triangle \mathrm{SBP}(\%)$ & $5.9 \pm 9.9$ & $5.7 \pm 10.2$ & $6.4 \pm 9.1$ & $5.0 \pm 9.7$ & $5.4 \pm 10.0$ & $3.7 \pm 8.6$ & $6.0 \pm 9.9$ & $5.7 \pm 10.2$ & $6.0 \pm 9.1$ \\
\hline
\end{tabular}

Values are expressed as mean \pm SD. ${ }^{\mathrm{a}} p<0.01$ compared to the corresponding subgroup before BWRP; ${ }^{\mathrm{b}} p<0.01$ compared to the subgroup aged $60-69$ years, including both females and males (i.e., total); ${ }^{c} p<0.01$ compared to the corresponding female subgroup of the same age. BWRP, body weight reduction program; GLU, glucose; T-C, total cholesterol; HDL-C, HDL cholesterol; DBP, diastolic blood pressure; SBP, systolic blood pressure. 
Table 3. CHD-R, FSS score and SCT time in the study population (before and after BWRP).

\begin{tabular}{|c|c|c|c|c|c|c|c|c|c|}
\hline \multirow[b]{2}{*}{ Outcome } & \multicolumn{3}{|c|}{ Total } & \multicolumn{3}{|c|}{ Males } & \multicolumn{3}{|c|}{ Females } \\
\hline & $>60$ Year & 60-69 Year & $>70$ Year & $>60$ Year & 60-69 Year & $>70$ Year & $>60$ Year & 60-69 Year & $>70$ Year \\
\hline PRE-CHD-R (points) & $10.2 \pm 3.5$ & $10.2 \pm 3.4$ & $10.1 \pm 3.6^{\mathrm{a}}$ & $8.6 \pm 2.9^{b}$ & $8.4 \pm 3.1^{b}$ & $9.0 \pm 2.3$ & $10.4 \pm 3.5$ & $10.5 \pm 3.4$ & $10.3 \pm 3.8^{c}$ \\
\hline POST-CHD-R (points) & $9.9 \pm 3.5^{\mathrm{d}}$ & $9.9 \pm 3.5^{\mathrm{d}}$ & $9.7 \pm 3.5^{d}$ & $7.3 \pm 2.5^{\mathrm{d}}$ & $7.1 \pm 2.7^{\mathrm{d}}$ & $7.9 \pm 1.5^{\mathrm{d}}$ & $10.3 \pm 3.5$ & $10.4 \pm 3.5$ & $10.0 \pm 3.6$ \\
\hline$\Delta \mathrm{CHD}-\mathrm{R}$ (points) & $0.4 \pm 2.7$ & $0.4 \pm 2.7$ & $0.6 \pm 2.6$ & $1.4 \pm 2.9^{b}$ & $1.4 \pm 2.9^{b}$ & $1.3 \pm 2.7^{\mathrm{c}}$ & $0.3 \pm 2.7$ & $0.2 \pm 2.7$ & $0.5 \pm 2.6$ \\
\hline PRE-FSS score (points) & $40.9 \pm 13.5$ & $40.1 \pm 13.7$ & $43.3 \pm 12.4$ & $36.2 \pm 13.1^{\mathrm{b}}$ & $35.2 \pm 13.2^{b}$ & $39.7 \pm 12.6$ & $41.7 \pm 13.4$ & $40.8 \pm 13.7$ & $43.9 \pm 12.3$ \\
\hline POST-FSS score (points) & $34.1 \pm 13.1^{\mathrm{d}}$ & $33.3 \pm 13.2^{d}$ & $36.2 \pm 12.4^{\mathrm{d}}$ & $30.1 \pm 11.2^{d}$ & $29.9 \pm 11.5^{d}$ & $31.1 \pm 10.3^{d}$ & $34.7 \pm 13.2^{d}$ & $33.8 \pm 13.4^{\mathrm{d}}$ & $36.9 \pm 12.5^{\mathrm{d}}$ \\
\hline$\Delta$ FSS score $(\%)$ & $16.4 \pm 18.5$ & $16.6 \pm 18.3$ & $15.8 \pm 18.9$ & $15.0 \pm 17.4$ & $13.8 \pm 16.0$ & $19.3 \pm 21.9$ & $16.6 \pm 18.6$ & $17.1 \pm 18.6$ & $15.4 \pm 18.7$ \\
\hline PRE-SCT time (sec) & $7.7 \pm 1.9$ & $7.6 \pm 1.8$ & $8.2 \pm 2.2$ & $6.8 \pm 1.5^{b}$ & $6.6 \pm 1.3^{b}$ & $7.4 \pm 2.0$ & $7.9 \pm 2.0$ & $7.8 \pm 1.9$ & $8.4 \pm 2.2$ \\
\hline POST-SCT time (sec) & $7.4 \pm 1.9^{\mathrm{d}}$ & $7.2 \pm 1.8^{\mathrm{d}}$ & $7.9 \pm 2.1^{\mathrm{d}}$ & $6.5 \pm 1.5^{\mathrm{d}}$ & $6.3 \pm 1.3^{d}$ & $7.2 \pm 2.0^{\mathrm{d}}$ & $7.5 \pm 1.9^{d}$ & $7.4 \pm 1.8^{\mathrm{d}}$ & $8.0 \pm 2.1^{\mathrm{d}}$ \\
\hline$\Delta \mathrm{SCT}$ time $(\%)$ & $4.3 \pm 4.7$ & $4.5 \pm 4.9$ & $4.0 \pm 4.2$ & $3.7 \pm 3.3$ & $3.8 \pm 3.5$ & $3.3 \pm 2.9$ & $4.5 \pm 4.9$ & $4.6 \pm 5.1$ & $4.1 \pm 4.4$ \\
\hline
\end{tabular}

Values are expressed as mean $\pm \mathrm{SD} .^{\text {a }} p<0.01$ compared to the subgroup aged $60-69$ years, including both females and males (i.e., total); ${ }^{\mathrm{b}} p<0.01$ compared to the corresponding female subgroup of the same age range; ${ }^{c} p<0.01$ compared to the female subgroup aged $60-69$ years. ${ }^{d} p<0.01$ compared to the corresponding subgroup before BWRP; BWRP, body weight reduction program; CHD-R, coronary heart disease risk; FSS, fatigue severity scale; SCT, stair climbing test. 
BWRP significantly reduced BW and BMI when considering all data, female and male groups and age- and gender-specific subgroups $(p<0.01)$ (Table 1; Figure 2). No significant differences in $\triangle \mathrm{BW}(\%)$ and $\triangle \mathrm{BMI}(\%)$ were observed among all subgroups, indicating a similar effectiveness of the intervention irrespectively from gender (females/males) and age ( $>60$ years, 60-69 years and $>70$ years) (Table 1; Figure 3). In particular, a $\triangle \mathrm{BMI}$ of $4.0 \pm 2.1 \%$ was found for all data (Table 1 ; Figure 3).
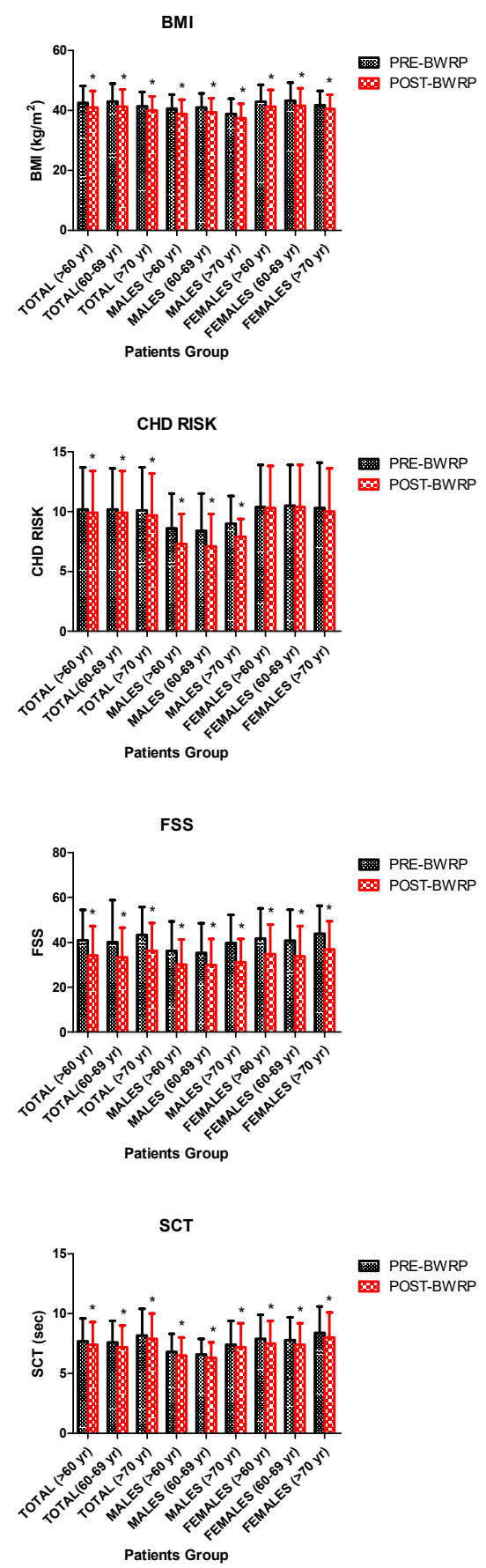

Figure 2. Body mass index (BMI, top panel), coronary heart disease risk (CHD RISK, top middle panel), fatigue severity scale (FSS) score (bottom middle panel) and stair climbing test (SCT) time (bottom panel) before and after a three-week body weight reduction program (BWRP) in elderly obese females and males. Data are expressed as mean \pm SD. The values corresponding to each gender- and age-related subgroup (total, females/males, $>60$ years, 60-69 years and $>70$ years) are reported. ${ }^{*} p<0.01$ compared to before body weight reduction program (BWRP). 

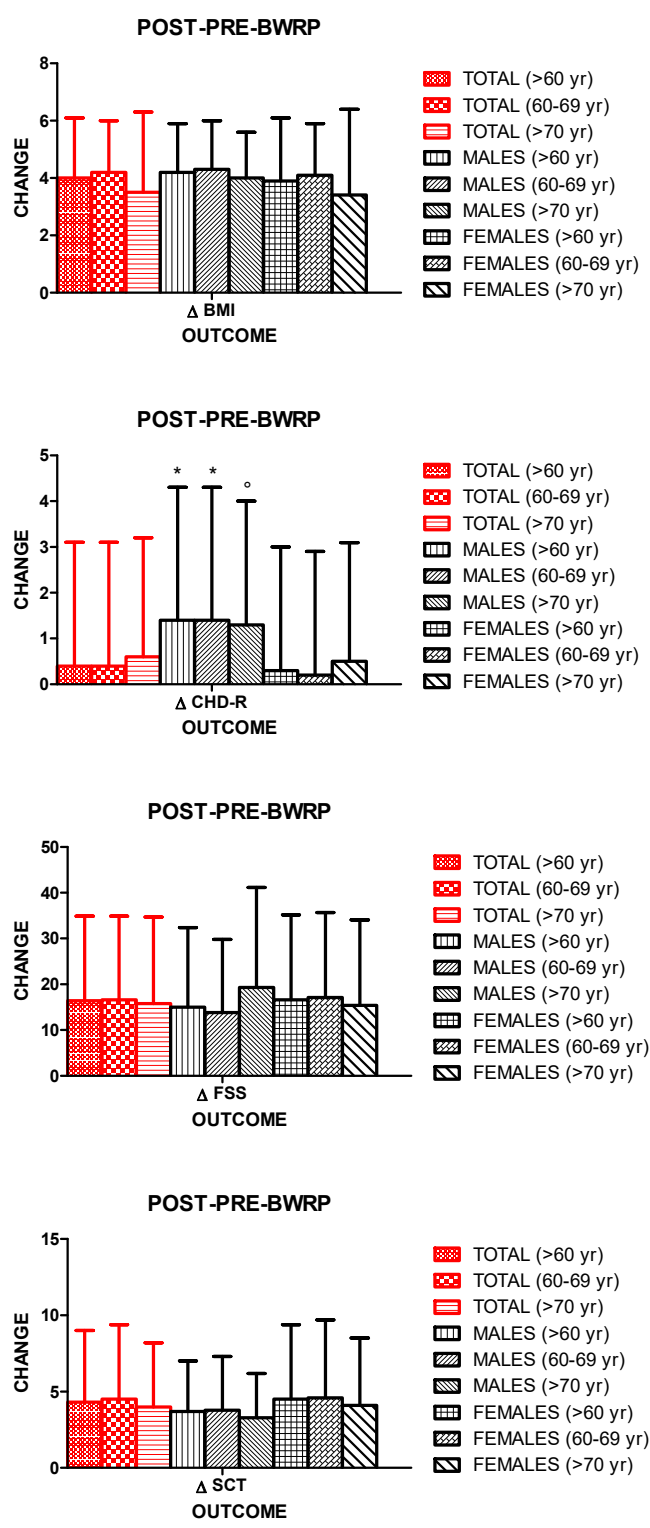

Figure 3. Changes of body mass index ( $\triangle \mathrm{BMI}$, top panel), coronary heart disease risk ( $\triangle \mathrm{CHD}-\mathrm{R}$, top middle panel), fatigue severity scale ( $\triangle \mathrm{FSS}$ ) score (bottom middle panel) and stair climbing test $(\Delta \mathrm{SCT})$ time (bottom panel) before and after a three-week body weight reduction program (POST-PRE-BWRP) in elderly obese females and males. Data are expressed as mean $\pm \mathrm{SD}$. The values corresponding to each gender- and age-related subgroup (total, females/males, $>60$ years, 60-69 years and $>70$ years) are reported. ${ }^{*} p<0.01$ compared to the corresponding female subgroup; ${ }^{\circ} p<0.01$ compared to females aged 60-69 years.

BWRP significantly reduced T-C and HDL-C in all subgroups (all, females/males, $>60$ years, $60-69$ years and $>70$ years) $(p<0.01)$ (Table 2$)$. Glucose was significantly reduced by BWRP when comparing each subgroup before and after the intervention $(p<0.01)$ (Table 2). No significant differences in $\triangle \mathrm{T}-\mathrm{C}, \triangle \mathrm{HDL}-\mathrm{C}$ and $\Delta \mathrm{GLU}(\%)$ were detected among all subgroups (Table 2). In particular, a $\triangle \mathrm{T}$-C, $\triangle \mathrm{HDL}-\mathrm{C}$ and $\Delta \mathrm{GLU}$ of $13.7 \pm 14.3 \%, 14.8 \pm 13.7 \%$ and $10.6 \pm 14.5 \%$, respectively, were found for all data (Table 2).

SBP and DBP were significantly reduced at the end of BWRP in all subgroups $(p<0.01)$, with the exception of DBP in males aged $>70$ years (Table 2). No significant differences in $\triangle \mathrm{SBP}$ and $\triangle \mathrm{DBP}$ (\%) were found among all subgroups (Table 2). In particular, a $\triangle \mathrm{SBP}$ and $\triangle \mathrm{DBP}$ of $5.9 \pm 9.9 \%$ and $3.2 \pm 11.7 \%$, respectively, were found for all data (Table 2 ). 
Due to the favorable effect of BWRP on BMI, T-C and BP, a significant decrease in CHD-R was observed at the end of the intervention in all subgroups $(p<0.01)$, with the exception of females aged $>60$ years, 60-69 years and $>70$ years (Table 3; Figure 2). Noteworthy, when pooling data from males and females, due to the positive contribution of males aged $>60$ years, whose CHD-R significantly decreased from $8.6 \pm 2.9$ to $7.3 \pm 2.5$, the pre-post-BWRP difference of CHD-R was significant in the two genders considered together (aged $>60$ years, $60-69$ years and $>70$ years) $(p<0.01)$ (Table 3; Figure 2). There were no significant differences in $\triangle \mathrm{CHD}-\mathrm{R}$ (absolute value) among male or female subgroups irrespectively from age ( $>60$ years, 60-69 years and $>70$ years); anyway, males aged $>60$ years or 60-69 years had a higher $\triangle$ CHD-R than that in the corresponding female subgroup $(p<0.01)$; furthermore, the $\triangle \mathrm{CHD}-\mathrm{R}$ in males aged $>70$ years was significantly higher than that in females aged $60-69$ years $(p<0.01)$, but not $>70$ years (Table 1 ; Figure 3$)$. When pooling data from females and males, $\triangle$ CHD-R was $0.4 \pm 2.7$.

BWRP significantly reduced FSS score and SCT time in all subgroups (all, females/males, $>60$ years, 60-69 years and $>70$ years) $(p<0.01)$ (Table 3; Figure 2$)$. There were no significant differences in the $\triangle$ FSS score and $\triangle \mathrm{SCT}$ time (\%) among all subgroups (Table 3; Figure 3). In particular, a $\Delta F S S$ score and $\triangle \mathrm{SCT}$ time of $16.4 \pm 18.5 \%$ and $4.3 \pm 4.7 \%$, respectively, were found for all data (Table 3; Figure 3).

Among all possible correlations, the most relevant were those between $\triangle \mathrm{BMI}(\%)$ and age $(r=-0.153, p<0.01)$ and between $\Delta$ FSS score $(\%)$ and age $(r=-0.0763, p<0.05)$ (Figure 4$)$.
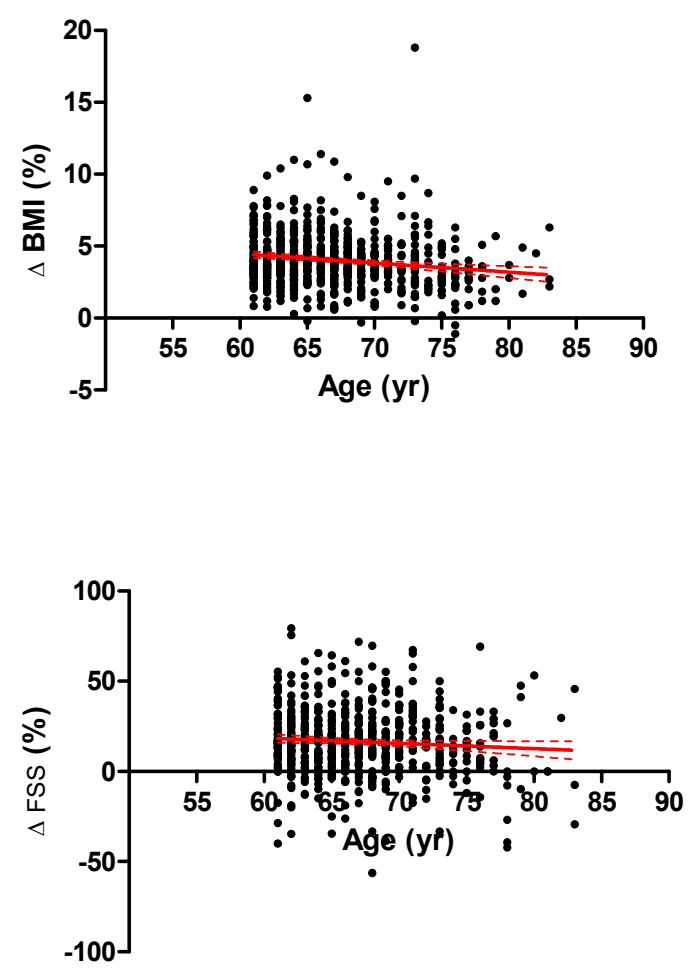

Figure 4. Correlations of age with changes in body mass index ( $\triangle \mathrm{BMI}$, top panel) or fatigue severity scale $(\triangle \mathrm{FSS}$, ) score (bottom panel) before and after a three-week body weight reduction program (POST-PRE-BWRP) in elderly obese females and males. The results of the linear regression analysis are reported (i.e., the best fitted line for all data together with $95 \%$ confidence interval).

\section{Discussion}

The main findings of the present study, carried out in a large cohort of elderly obese females and males, undergoing a three-week multidisciplinary BWRP, including hypocaloric diet, physical activity and psychological counseling, can be summarized in the following key points: (1) BWRP is capable of reducing $B W$ and $B M I$ in an obese geriatric population, including patients aged $>70$ years, the effects being similar to those obtained in young obese adults (a $\triangle \mathrm{BMI}$ of about $4 \%$ ) [21,27,31,32]; (2) BWRP 
improves some cardiovascular risk factors, such as T-C, glucose, SBP and DBP, with the ensuing reduction of CHD-R (a $\triangle$ CHD-R of about 0.4 points), an effect more evident in all male subgroups irrespectively from age; (3) BWRP reduces the FSS score and SCT time, indicating beneficial effects on fatigue in daily activities and motor performance, which are requisites to obtain a better functional autonomy in the later life [33]; (4) an age-dependent reduction in $\triangle \mathrm{BMI}$ and $\Delta \mathrm{FSS}$ score is present, the decline between 60 and 80 years being however relatively modest, indicating that BWRP is able to produce beneficial effects even in advanced age.

As stated in recent recommendations by the most important scientific societies in clinical nutrition, geriatrics and obesiology [9], any BWRP administered in elderly obese patients, in addition to reduce obesity-associated medical complications, ought to focus on improving physical function and quality of life.

Reportedly, fatigue is a highly prevalent symptom in obese subjects irrespectively from age, but the prevalence further increases in the geriatric population due to other comorbidities such as osteoarthritis and sarcopenia, which generally are not present in young subjects [24,34]. An obese patient complaining of fatigue can be trapped in a vicious circle because fatigue reduces physical activity and a sedentary state promotes weight gain, with a negative impact on the quality of life $[35,36]$.

As shown in the present study, BWRP significantly reduced both BW and FSS score in all subgroups of patients (male/female or $>60$ years, 60-69 years and $>70$ years); nevertheless, no correlation was found between the $\triangle \mathrm{BMI}$ and $\triangle \mathrm{FSS}$ score. These findings seem to suggest that the beneficial effects of BWRP on fatigue are not uniquely a consequence of the weight loss and the improved physical agility per se, but also due to a perceived psychological well being [37]. In this context, it is noteworthy to recall the mood-elevating effect of exercise, even when practiced moderately, which can modulate monoaminergic neurotransmission, which governs physical symptoms, including fatigue [38].

SCT is a validated and simple test to assess the maximally attainable lower limbs muscle power output $[22,23]$. In the present study, the SCT time was shown to improve after BWRP. The relevance of this finding relies on the demographic characteristics of the recruited population, consisting in elderly obese subjects, for whom execution of the test may be more difficult for many age- and not only BW-related reasons in comparison with a younger group [33]. Different factors (i.e., reduction of BW, shift in the balance between parasympathetic and sympathetic activities, central and peripheral adaptations with more efficient muscle contractions and a more favorable left shift of the muscle power-velocity curve, acquisition of motor skillfulness and coordination during the repeated trials, increased self-esteem and motivation) might be invoked, alone or in combination, to explain the positive effects of BMRP on SCT-related motor performance [22,23]. Since a high level of physical activity has been shown to increase the odds of a healthy aging and protect the "frail" elderly patient independently from any effect on BW [39], any effort should be made to engage elderly obese subjects in a BWRP, appropriately tailored to patient's clinical needs.

The advantage of a (even partially) restored physical agility in an elderly obese subject undergoing a BWRP might overcome the cardiometabolic benefits (see below) or contrast the so-called "obesity paradox", a debated issue for which there would be a survival advantage in overweight/obese patients, calling into question the importance of weight loss particularly in geriatric population [19].

The present study confirms the effectiveness of our BWRP to reduce the CHD-R in elderly obese patients [40]. Though the duration of the BWRP was limited (only three weeks), the cardiometabolic benefits were relevant as shown by a $\triangle \mathrm{CHD}-\mathrm{R}$ of about 0.4 points, which might correspond to a decreased (not uniquely cardiovascular) mortality over a long time interval, particularly in the subjects aged 60-69 years. Though the imposition of a healthy life style is fundamental to maintain the cardiometabolic benefits produced by a (previous) BWRP over time [41], epidemiological studies in a large geriatric population are mandatory to detract the theory of the "obesity paradox", including the elimination of methodological biases such as elderly obese patients for whom a catabolic state due to a BWPR would represent a precipitating factor of other pre-existing critical diseases (e.g., oncological or cardiological conditions) [42]. 
In the present study, $\triangle$ CHD-R was higher in males than females and similar among all male subgroups ( $>60$ years, $60-69$ years and $>70$ years); furthermore, BWRP did not significantly reduce CHD-R in female subgroups. These findings are not surprising. In fact, as shown by other studies [43], there is a dramatic increase of CHD-R in females during the menopausal transition, for whom the well-known cardioprotective effects of (endogenous) estrogens are missing [44].

Nevertheless, due to the multisystemic benefits that are produced by a BWRP in both males and females, post-menopausal women, who epidemiologically have a longer life expectancy than men [45] and have a higher risk of weight gain because of the hypoestrogenism [5], should be encouraged to take part in any BWRP to obtain other benefits, e.g., increased motor performance.

Though statistically significant, the correlations of age with the $\triangle \mathrm{BMI}$ or $\Delta \mathrm{FSS}$ score do not represent a valid reason to exclude the very elderly subject from a BWRP. In fact, the age-dependent decline of BWRP effectiveness appears to be modest and, despite this fact, as reported above, the BWRP-induced benefits are evident in all subgroups, including subjects aged $>70$ years. In our opinion, this age-dependent hyporesponsiveness should be further investigated to better optimize the BWRP for very elderly subjects, who could have different clinical needs [7-10,14].

In conclusion, though only a limited number of outcomes was investigated, the present study shows that a $4 \%$ BW reduction following a multidisciplinary BWRP in severely elderly obese patients is associated with positive multisystemic effects, particularly, muscle-skeletal and cardiometabolic benefits, which can favorably influence their general well-being and improve the autonomy level in performing the more common daily activities. The maintenance of healthy life styles, including controlled food intake and regular physical activity, after a period of metabolic rehabilitation (i.e., BWRP), which can be repeated and/or personalized when needed, is strongly recommended in all elderly obese patients to improve their clinical condition and autonomy level [41].

Author Contributions: A.S. designed the study. L.A., A.D.C., S.T., D.C. and S.C. enrolled the subjects and administered the FSS; R.D.M. and G.T. performed SCT and calculated the CHD-R. N.M., S.T., A.D.C., L.A., D.C., S.C., G.T. and R.D.M. elaborated the database. A.E.R. analyzed the data and, together with A.S., wrote the manuscript. S.G.C. contributed to data interpretation and discussion writing. All authors contributed to the manuscript revision.

Funding: The study was supported by Progetti di Ricerca Corrente, Istituto Auxologico Italiano, IRCCS, Milan, Italy.

Acknowledgments: The authors thank the nursing staff at the Division of Metabolic Diseases, Istituto Auxologico Italiano, Piancavallo, VB, Italy. Our special thanks go to the subjects for their willingness to participate in this research.

Conflicts of Interest: The authors declare no conflict of interest.

Availability of Data and Materials: The datasets used and/or analyzed in the present study are available from the corresponding author on reasonable request.

\section{References}

1. Flegal, K.M.; Kruszon-Moran, D.; Carroll, M.D.; Fryar, C.D.; Ogden, C.L. Trends in obesity among adults in theUnited States, 2005 to 2014. JAMA 2016, 315, 2284-2291. [CrossRef] [PubMed]

2. Ng, M.; Fleming, T.; Robinson, M.; Thomson, B.; Graetz, N.; Margono, C.; Mullany, E.C.; Biryukov, S.; Abbafati, C.; Abera, S.F.; et al. Global, regional, and national prevalence of overweight and obesity in children and adults during 1980-2013: A systematic analysis for the Global Burden of Disease Study 2013. Lancet 2014, 384, 766-781. [CrossRef]

3. Amarya, S.; Singh, K.; Sabharwal, M. Health consequences of obesity in the elderly. J. Clin. Gerontol. Geriatr. 2014, 5, 63-67. [CrossRef]

4. Bales, C.W.; Porter Starr, K.N. Obesity interventions for older adults: Diet as a determinant of physical function. Adv. Nutr. 2018, 9, 151-159. [CrossRef] [PubMed]

5. Brown, T.J. Health benefits of weight reduction in postmenopausal women: A systematic review. J. Br. Menopause Soc. 2006, 12, 164-171. [CrossRef] 
6. Locher, J.L.; Goldsby, T.U.; Goss, A.M.; Kilgore, M.L.; Gower, B.; Ard, J.D. Calorie restriction in overweight older adults: Do benefits exceed potential risks? Exp. Gerontol. 2016, 86, 4-13. [CrossRef] [PubMed]

7. Tzankoff, S.P.; Norris, A.H. Effect of muscle mass decrease on age-related BMR changes. J. Appl. Physiol. Respir. Environ. Exerc. Physiol. 1977, 43, 1001-1006. [CrossRef]

8. Elia, M.; Ritz, P.; Stubbs, R.J. Total energy expenditure in the elderly. Eur. J. Clin. Nutr. 2000, 54 (Suppl. 3), S92-S103. [CrossRef] [PubMed]

9. Villareal, D.T.; Apovian, C.M.; Kushner, R.F.; Klein, S. Obesity in older adults: Technical review and position statement of the American Society for Nutrition and NAASO, The Obesity Society. Am. J. Clin. Nutr. 2005, 82, 923-934. [CrossRef]

10. Ten Haaf, T.; Verreijen, A.M.; Memelink, R.G.; Tieland, M.; Weijs, P.J. Reduction in energy expenditure during weight loss is higher than predicted based on fat free mass and fat mass in older adults. Clin. Nutr. 2018, 37, 250-253. [CrossRef]

11. Porter Starr, K.N.; McDonald, S.R.; Bales, C.W. Obesity and physical frailty in older adults: A scoping review of lifestyle intervention trials. J. Am. Med. Dir. Assoc. 2014, 15, 240-250. [CrossRef] [PubMed]

12. Costamagna, D.; Costelli, P.; Sampaolesi, M.; Penna, F. Role of inflammation in muscle homeostasis and myogenesis. Mediat. Inflamm. 2015, 2015, 805172. [CrossRef] [PubMed]

13. Weinheimer, E.M.; Sands, L.P.; Campbell, W.W. A systematic review of the separate and combined effects of energy restriction and exercise on fat-free mass in middle-aged and older adults: Implications for sarcopenic obesity. Nutr. Rev. 2010, 68, 375-388. [CrossRef]

14. Kalyani, R.R.; Metter, E.J.; Ramachandran, R.; Chia, C.W.; Saudek, C.D. Glucose and insulin measurements from the oral glucose tolerance test and relationship to muscle mass. J. Gerontol. Ser. A Biol. Sci. Med. Sci. 2012, 67, 74-81. [CrossRef] [PubMed]

15. Giunta, M.; Rigamonti, A.E.; Agosti, F.; Patrizi, A.; Compri, E.; Cardinale, M.; Sartorio, A. Combination of external load and whole body vibration potentiates the GH-releasing effect of squatting in healthy females. Horm. Metab. Res. 2013, 45, 611-666. [CrossRef] [PubMed]

16. Sartorio, A.; Lafortuna, C.L.; Maffiuletti, N.A.; Agosti, F.; Marazzi, N.; Rastelli, F.; Rigamonti, A.E.; Muller, E.E. $\mathrm{GH}$ responses to two consecutive bouts of whole body vibration, maximal voluntary contractions or vibration alternated with maximal voluntary contractions administered at 2-h intervals in healthy adults. Growth Horm. IGF Res. 2010, 20, 416-421. [CrossRef] [PubMed]

17. Rigamonti, A.E.; Locatelli, L.; Cella, S.G.; Bonomo, S.M.; Giunta, M.; Molinari, F.; Sartorio, A.; Müller, E.E. Muscle expressions of MGF, IGF-IEa, and myostatin in intact and hypophysectomized rats: Effects of rhGH and testosterone alone or combined. Horm. Metab. Res. 2009, 41, 23-29. [CrossRef] [PubMed]

18. Soltani, S.; Hunter, G.R.; Kazemi, A.; Shab-Bidar, S. The effects of weight loss approaches on bone mineral density in adults: A systematic review and meta-analysis of randomized controlled trials. Osteoporos. Int. 2016, 27, 2655-2671. [CrossRef]

19. Wang, S.; Ren, J. Obesity paradox in aging: From prevalence to pathophysiology. Prog. Cardiovasc. Dis. 2018, 61, 182-189. [CrossRef] [PubMed]

20. Evans, W.J.; Morley, J.E.; Argiles, J.; Bales, C.; Baracos, V.; Guttridge, D.; Jatoi, A.; Kalantar-Zadeh, K.; Lochs, H.; Mantovani, G.; et al. Cachexia: A new definition. Clin. Nutr. 2008, 27, 793-799. [CrossRef]

21. Sartorio, A.; Lafortuna, C.L.; Marinone, P.G.; Tavani, A.; La Vecchia, C.; Bosetti, C. Short-term effects of two integrated, non-pharmacological body weight reduction programs on coronary heart disease risk factors in young obese patients. Diab. Nutr. Metab. 2003, 16, 262-265.

22. Sartorio, A.; Lafortuna, C.L.; Conte, G.; Faglia, G.; Narici, M.V. Changes in motor control and muscle performance after a short-term body mass reduction program in obese subjects. J. Endocrinol. Investig. 2001, 24, 393-398. [CrossRef] [PubMed]

23. Sartorio, A.; Narici, M.V.; Fumagalli, E.; Faglia, G.; Lafortuna, C.L. Aerobic and anaerobic performance before and after a short-term body mass reduction program in obese subjects. Diab. Nutr. Metab. 2001, 14, 51-57.

24. Impellizzeri, F.M.; Agosti, F.; De Col, A.; Sartorio, A. Psychometric properties of the Fatigue Severity Scale in obese patients. Health Qual. Life Outcomes 2013, 11, 32. [CrossRef]

25. Sartorio, A.; Proietti, M.; Marinone, P.G.; Agosti, F.; Adorni, F.; Lafortuna, C.L. Influence of gender, age and $\mathrm{BMI}$ on lower limb muscular power output in a large population of obese men and women. Int. J. Obes. 2004, 28, 91-98. [CrossRef] [PubMed] 
26. Margaria, R.; Aghemo, P.; Rovelli, E. Measurement of muscular power (anaerobic) in man. J. Appl. Physiol. 1966, 21, 1662-1664. [CrossRef]

27. Sartorio, A.; Fontana, P.; Trecate, L.; Lafortuna, C.L. Short-term changes of fatigue and muscle performance in severe obese patients after an integrated body mass reduction program. Diab. Nutr. Metab. 2003, 16, 88-93.

28. Hjollund, N.H.; Andersen, J.H.; Bech, P. Assessment of fatigue in chronic disease: A bibliographic study of fatigue measurement scales. Health Qual. Life Outcomes 2007, 5, 12. [CrossRef]

29. Elbers, R.G.; Rietberg, M.B.; van Wegen, E.E.; Verhoef, J.; Kramer, S.F.; Terwee, C.B.; Kwakkel, G. Self-report fatigue questionnaires in multiple sclerosis, Parkinson's disease and stroke: A systematic review of measurement properties. Qual. Life Res. 2012, 21, 925-944. [CrossRef]

30. Wilson, P.W.F.; D'Agostino, R.B.; Levy, D.; Belanger, A.M.; Silbershats, H.; Kannel, W.B. Prediction of coronary hearth disease using risk factor categories. Circulation 1998, 97, 1837-1847. [CrossRef]

31. Rigamonti, A.E.; Piscitelli, F.; Aveta, T.; Agosti, F.; De Col, A.; Bini, S.; Cella, S.G.; Di Marzo, V.; Sartorio, A. Anticipatory and consummatory effects of (hedonic) chocolate intake are associated with increased circulating levels of the orexigenic peptide ghrelin and endocannabinoids in obese adults. Food Nutr. Res. 2015, 59, 29678. [CrossRef] [PubMed]

32. Rigamonti, A.E.; Resnik, M.; Compri, E.; Agosti, F.; De Col, A.; Monteleone, P.; Marazzi, N.; Bonomo, S.M.; Müller, E.E.; Sartorio, A. The cholestyramine-induced decrease of PYY postprandial response is negatively correlated with fat mass in obese women. Horm. Metab. Res. 2011, 43, 569-573. [CrossRef] [PubMed]

33. Jensen, G.L. Obesity and functional decline: Epidemiology and geriatric consequences. Clin. Geriatr. Med. 2005, 21, 677-687. [CrossRef]

34. Moreh, E.; Jacobs, J.M.; Stessman, J. Fatigue, function, and mortality in older adults. J. Gerontol. Ser. A Biol. Sci. Med. Sci. 2010, 65, 887-895. [CrossRef] [PubMed]

35. Fritschi, C.; Quinn, L. Fatigue in patients with diabetes: A review. J. Psychosom. Res. 2010, 69, 33-41. [CrossRef]

36. Singh, R.; Teel, C.; Sabus, C.; McGinnis, P.; Kluding, P. Fatigue in Type 2 Diabetes: Impact on Quality of Life and Predictors. PLoS ONE 2016, 11, e0165652. [CrossRef]

37. Ten Hoor, G.A.; Kok, G.; Peters, G.Y.; Frissen, T.; Schols, A.M.; Plasqui, G. The psychological effects of strength exercises in people who are overweight or obese: A systematic review. Sports Med. 2017, 47, 2069-2081. [CrossRef]

38. Lin, T.W.; Kuo, Y.M. Exercise benefits brain function: The monoamine connection. Brain Sci. 2013, 3, 39-53. [CrossRef] [PubMed]

39. Liao, C.D.; Lee, P.H.; Hsiao, D.J.; Huang, S.W.; Tsauo, J.Y.; Chen, H.C.; Liou, T.H. Effects of protein supplementation combined with exercise intervention on frailty indices, body composition, and physical function in frail older adults. Nutrients 2018, 10, 1916. [CrossRef] [PubMed]

40. Cottell, K.E.; Dorfman, L.R.; Straight, C.R.; Delmonico, M.J.; Lofgren, I.E. The effects of diet education plus light resistance training on coronary heart disease risk factors in community-dwelling older adults. J. Nutr. Health Aging 2011, 15, 762-767. [CrossRef] [PubMed]

41. Wadden, T.A.; Butryn, M.L.; Byrne, K.J. Efficacy of lifestyle modification for long-term weight control. Obes. Res. 2004, 12 (Suppl. 12), 151S-162S. [CrossRef]

42. Braun, N.; Gomes, F.; Schütz, P. "The obesity paradox" in disease-Is the protective effect of obesity true? Swiss Med. Wkly. 2015, 145, w14265. [CrossRef] [PubMed]

43. Wells, G.L. Cardiovascular risk factors: Does sex matter? Curr. Vasc. Pharmacol. 2016, 14, 452-457. [CrossRef] [PubMed]

44. Kallen, A.N.; Pal, L. Cardiovascular disease and ovarian function. Curr. Opin. Obstet. Gynecol. 2011, 23, 258-267. [CrossRef] [PubMed]

45. Barford, A.; Dorling, D.; Davey Smith, G.; Shaw, M. Life expectancy: Women now on top everywhere. BMJ 2006, 332, 808 .

(C) 2019 by the authors. Licensee MDPI, Basel, Switzerland. This article is an open access article distributed under the terms and conditions of the Creative Commons Attribution (CC BY) license (http://creativecommons.org/licenses/by/4.0/). 